\title{
REPERCUSSÕES DA VIOLÊNCIA PARA OS ADOLESCENTES
}

\author{
Vanessa Cedraz dos Santos ${ }^{1}$; Aisiane Cedraz Morais ${ }^{2}$; Sinara de Lima Souza ${ }^{3}$ \\ 1.Bolsista PIBIC/CNPq, Graduanda em Enfermagem, Universidade Estadual de Feira de Santana, integrante do \\ NIVS. e-mail: vanessacedraz@gmail.com \\ 2. Orientador, Departamento de Saúde - DSAU, Universidade Estadual de Feira de Santana, Pesquisadora do \\ NIEVS, e-mail: aisicedraz@hotmail.com \\ 3. Coordenadora do Núcleo Interdisciplinar de Estudo sobre Vulnerabilidade em Saúde - NIEVS, Departamento de Saúde - \\ DSAU, Universidade Estadual de Feira de Santana, e-mail: sinarals@uefs.com
}

PALAVRAS-CHAVE: Violência; Adolescentes; Pesquisa-Ação.

\section{INTRODUÇÃOO}

Considerado um problema de saúde pública mundial, a violência é um fenômeno oriundo de interações individuais e coletivas, que submete os adolescentes a situações de discriminação, negligência e abandono, gerando danos físicos, emocionais, espirituais, entre outros (MOREIRA et al, 2016; SANTOS et al, 2018; HILDEBRAND et al, 2019). No tocante as repercussões da violência, as mesmas podem cessar, impedir ou retardar o desenvolvimento social, emocional, cognitivo e psicológico dos adolescentes que pode perdurar por toda a vida ou ainda potencializar o risco para psicopatologias e provocar comportamentos prejudiciais à saúde (BRASIL, 2010). Sendo a violência um fenômeno de ampla magnitude, justifica-se a realização deste estudo, devido a relevância da compreensão dos impactos da violência para os adolescentes de uma cidade com tantas manifestações cotidianas de violência. Os objetivos específicos desse estudo são descrever a percepção sobre as situações de violência; e os impactos da violência na qualidade de vida dos adolescentes. Assim, partindo do questionamento de quais as repercussões da violência para os adolescentes, na perspectiva de um projeto de pesquisa ação, que pretende não somente responder a este questionamento de pesquisa, mas também propor estratégias para a construção de territórios de paz.

\section{METODOLOGIA}

Trata-se de uma pesquisa qualitativa, que foi realizada como subprojeto da pesquisa "Diagnóstico da violência e estratégias de construção da paz nas escolas municipais de Feira de Santana-BA" (PROVESC, aprovação CONSEPE 039/2012). Trata-se de uma pesquisa-ação com o intuito de "identificar os problemas, buscar soluções e implementar possíveis ações coletivamente deliberadas" (THIOLLENT, 2001, p. 32). Os participantes do estudo foram os adolescentes na faixa etária entre 12 a 19 anos, da Escola Municipal Rosa Maria Esperidião Leite (Matinha dos Pretos), do turno matutino. Utilizou como técnicas de coleta de dados a entrevista semi-estruturada. Ressalta-se que as coletas foram realizadas após as assinaturas do termo de assentimento (TALE) e de consentimento (TCLE) e foram preservados o anonimato e confidencialidade dos entrevistados. As entrevistas foram submetidas a Análise de Conteúdo, de acordo com a abordagem de Bardin, que é operacionalizada em três etapas: 1. Pré-Análise: 2. Exploração do Material e 3. Tratamento dos resultados obtidos e Interpretação (BARDIN, 2011). A realização desta investigação foi pautada em todos os preceitos éticos que envolvem Seres Humanos, em todas as fases da pesquisa. O projeto foi avaliado pelo CEP/UEFS, que emitiu parecer de aprovação com Protocolo n ${ }^{\circ}$ 152/2010, CAE 0150.0.059.000-10.

\section{RESULTADOS E DISCUSSÃO}

Os resultados desta pesquisa foram alcançados através das entrevistas fornecidas início do mês de março de 2020 por três adolescentes, na própria escola durante o intervalo das aulas em uma sala reservada. Foram garantidas a privacidade e a preservação das identidades dos adolescentes e o sigilo das informações. Para a identificação dos participantes da pesquisa, foram utilizadas as letras AD (referente a palavra adolescente) seguida de um número de ordem (ex.: AD 01, 
AD 02, AD 03). As falas foram transcritas na íntegra e os dados produzidos foram interpretados através da análise de conteúdo temática proposta. Diante disso, visando compreender as repercussões da violência na vida dos adolescentes e a sua percepção sobre a violência, desenvolveu-se quatro categorias conforme as falas dos entrevistados: Formas de violência, Fatores que contribuem para a violência, Locais que vivenciaram a violência e Consequências da violência. A seguir, serão apresentados algumas falas dos entrevistados conforme cada categoria.

Formas de violência: agressão física e verbal, preconceito, abuso sexual, homicídio: Essa categoria aborda sobre a percepção dos adolescentes em relação a violência, esta, é considerada um problema de saúde pública cuja repercussões provocam efeitos deletérios. Quando questionados a respeito do seu entendimento sobre a violência, os adolescentes apontam visões diferentes da violência. As falas a seguir, referem a violência quanto à natureza:

(...). Porque violência não é só agredir né? Também tem a violência verbal (AD 01).

(...) física é quando bate uma pessoa e verbal é quando xinga, fala coisas que... machucam, essas coisas. Eu acho que deve ser isso (AD 02).

A violência física compromete a integridade física da vítima, provocado pelo uso da força através de socos, queimaduras, pontapés, empurrões e estrangulamentos, ocasionando lesões e traumas podendo também provocar a morte. No que concerne à violência verbal, esta, se configura uma violência psicológica, tendo como finalidade humilhar, apavorar e intimidar a vítima (TOLEDO (org.), 2013). Um dos adolescentes exprime sua opinião relacionando o preconceito como uma forma de violência, evidenciado na seguinte fala:

Eu não sei se o preconceito é um tipo de violência, mas eu acho que é, mas quando uma pessoa está sofrendo um preconceito por outra, a outra tá chamando de negro, disso, daquilo, eu já me sinto mal (AD 01).

O preconceito racial é descrito como "uma disposição (ou atitude) desfavorável, culturalmente condicionada, em relação aos membros de uma população, aos quais se têm como estigmatizados, seja devido à aparência, seja devido a toda ou parte da ascendência étnica que se lhes atribui ou reconhece" (NOGUEIRA, 2006, p. 292).

Fatores que contribuem para a violência: sentimento de superioridade, condição socioeconômica, transtorno, interesse em "diminuir" o próximo, influência das pessoas e ciúmes: Nessa categoria foram agrupados os conteúdos referentes aos fatores que contribuem para a ocorrência da violência. A fala a seguir, associa aos atos violentos o comportamento de superioridade:

(...) a pessoa que pratica a violência, tem superioridade a outra pessoa (AD 01).

Segundo Amorim (2015), o sentimento de superioridade na perspectiva do Alfred Adler advém do domínio e da agressividade, portanto, a necessidade desse sentimento é provocada através da autoridade e controle sobre outros indivíduos.

O ciúme também é citado como um dos fatores para a ocorrência de comportamentos violentos, ou seja, um sentimento gerador da violência:

(...) mas eu briguei por causa de kkkkkk namorado. Porque eu já estava com ciúmes.

(...) E violência não é bom né? (AD 02).

Mallmann (2015), apresenta o ciúme sob a ótica do Freud, que consiste em um sentimento participativo das relações entre os indivíduos. Salienta-se o seu excesso demonstra uma patologia.

Locais que vivenciaram a violência: escola, casa e comunidade: Referente a essa categoria, é apresentado as verbalizações dos entrevistados no que diz respeito a sua vivência com alguma situação de violência. $\mathrm{O}$ seguinte relato descreve uma situação vivenciada na escola: 
Ahh que eu já vivenciei, eu acho que eu vivencio mais na escola. A escola é o ponto pra violência, eu acho. Mas uma violência que pra mim eu não suporto, é abuso. (...) eu vejo as meninas passando pelo corredor os meninos faz, é... assobia, fala assim: hummm que gostosa (...) (AD 01).

O ambiente escolar também é um local de ocorrência da violência. Segundo Silva et al (2014, p. 21), "a violência sofrida, ou praticada, nas escolas se manifesta de forma distinta e sofre influências das condições de extrato social, tipo de instituição, cultura e gênero". A seguinte fala expressa sobre a sua vivência no tocante a violência, citando os casos de homicídios ocorridos na sua comunidade:

É... porque aqui teve muito caso de violência, aqui na escola e fora. É... briga e fora da escola já teve até morte (AD 03).

No Brasil, houve um aumento de $350 \%$ entre 2016 e 2017 dos assassinatos de pessoas de comunidades quilombolas, de quatro para dezoito vítimas conforme o relatório Racismo e violência contra quilombos no Brasil (OLIVEIRA, 2018).

Consequências da violência: depressão e morte; tristeza, sente-se mal e ruim: Essa categoria, apresenta algumas das repercussões da violência da vida das vítimas ou das pessoas que vivenciaram episódios de violência, segundo os entrevistados. Citada por um dos adolescentes, a depressão é um dos impactos para as vítimas de violência sexual:

(...) Entra em uma depressão quando a pessoa sofre abuso sexual (AD 01)

A depressão ou melancolia é um transtorno psicológico caracterizado por alteração no humor (tristeza, solidão e apatia), autoconceito negativo associado a autoacusações, alterações vegetativas (anorexia e insônia) e alteração de atividades (agitação ou retardo psicomotor), com intensidade variando de leve a grave (BECK; ALFORD, 2011).

Para as pessoas que não foram vítimas, mas que presenciaram ou que ouviram sobre situações de violência, tais episódios também repercutem negativamente, as falas a seguir expressam tais sentimentos:

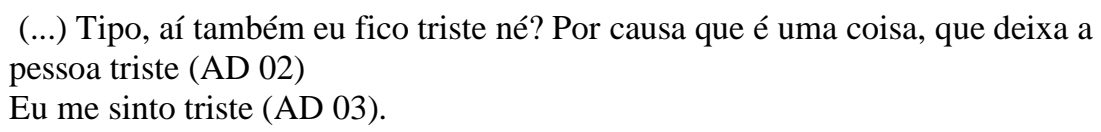

A violência é multifatorial e afeta todos indivíduos. Para a sociedade os desafios de resolutividade e os impactos financeiros, a busca pelo enfrentamento e a prevenção, já no âmbito da saúde a abordagem em relação a assistência às vítimas como a promoção e restauração da saúde.

\section{CONSIDERAÇÕES FINAIS}

Ao analisar a percepção dos adolescentes sobre a violência e suas repercussões, observa-se diferentes visões sobre o que a violência. $\mathrm{O}$ enfrentamento da violência pela sociedade ainda é um desafio e suas repercussões estabelecem a necessidade do combate ao ciclo da violência. Ocorre a vulnerabilidade de certos grupos populacionais nos quais representam as principais vítimas da violência, como: jovens negros, mulheres e crianças. A violência, além de causar danos à saúde e interferir no desenvolvimento humano, é também uma violação dos direitos. Reverbera intensa e negativamente nas condições físicas e psicossociais das vítimas, principalmente durante a adolescência. Os efeitos da violência nessa fase da vida corroboram para comportamentos prejudiciais e a exposição a situações de risco, tais como: uso de bebidas alcoólicas e drogas ilícitas, perpetuação de atos violentos, comprometimentos no aprendizado, evasão escolar, envolvimentos com grupos que atuam na ilegalidade, depressão, ideação suicida, suicídio e morte. Adolescentes negros e pobres vivenciam rotineiramente condutas violentas em seus diversos contextos e perpetradas por diversos atores. São as principais vítimas dos assassinatos, das agressões, das abordagens policias violentas, encarceramentos, 
preconceito e racismo. Assim, urge que as políticas publicas possam intervir de forma positiva a fim de diminuir a violência e paralelamente propagar a Cultura de Paz, envolvendo famílias, escolas e sociedade de forma geral.

\section{REFERÊNCIAS}

AMORIM, Jamilly de Sousa. Agressividade e luta pela superioridade, segundo Alfred Adler. Psicologiapersonal1.wixsite, 2015. Disponível em:< https://psicologiapersonal1.wixsite.com/teoriaspersonalidade/singlepost/2015/11/02/Agressividade-e-luta-pela-superioridade-segundo-Alfred-Adler. Acesso em: 02 jul. 2020.

BARDIN, Laurence. Análise de conteúdo. São Paulo: Edições 70, 2011.

BECK, Aaron T.; ALFORD, Brad A. Depressão: causas e tratamento. $2^{a}$ ed. Artmed: Porto Alegre, 2011.

BRASIL. Ministério da Saúde. Secretaria de Atenção à Saúde. Departamento de Ações Programáticas Estratégicas. Impacto da Violência na Saúde das Crianças e Adolescentes. 1. ed., 1. reimpr. Brasília: Editora do Ministério da Saúde, 2010. Disponível em: < http://bvsms.saude.gov.br/bvs/publicacoes/impacto_violencia_saude_criancas_adolescentes.p df> Acesso em: 18 de mar. 2019.

MALlmANN, Cleo José. Ciúmes: do normal ao patológico. Estudos de Psicanálise | Belo Horizonte-MG | n. 43 | p. 43-50 | julho/2015. Disponível em:< http://www.cbp.org.br/n43a04.pdf>. Acesso em: 03 de jul. 2020.

MOREIRA, Michelle Araújo et al. Impactos da violência perpetrada contra adolescentes na qualidade de vida. Arq. Ciênc. Saúde. 2016 out-dez; 23(4) 54-60. Disponível em: < http://www.cienciasdasaude.famerp.br/index.php/racs/article/view/484/238> Acesso em: 18 de mar. 2019.

NOGUEIRA, Oracy. Preconceito racial de marca e preconceito racial de origem: Sugestão de um quadro de referência para a interpretação do material sobre relações raciais no Brasil. Tempo Social, revista de sociologia da USP, v. 19, n. 1. Nov. 2006. Disponível em: < https://www.scielo.br/pdf/ts/v19n1/a15v19n1.pdf> Acesso em: 01 de jul. 2020.

OLIVEIRA, Ana Luíza Matos de. Racismo: assassinatos de quilombolas crescem $350 \%$. Fpabramo.org.br, 2018. Disponível em: < https://fpabramo.org.br/2018/09/27/facetas-docrescente-racismo-assassinatos-de-quilombolas-crescem-350/>. Acesso em: 06 de jul. 2020. SANTOS, Marconi de Jesus et al. Caracterização da violência sexual contra crianças e adolescentes na escola - Brasil, 2010-2014. Epidemiol. Serv. Saude, Brasília, 27(2):e2017059, 2018. Disponível em : <https://scielosp.org/pdf/ress/2018.v27n2/e2017059/pt> Acesso em: 18 de mar. 2019. SILVA, Ethel Bastos da et al. Violência escolar na perspectiva de adolescentes: potencialidades para o enfrentamento. Cogitare Enferm. 2014 Jan/Mar; 19(1):20-6. Disponível em:< https://revistas.ufpr.br/cogitare/article/view/35926/22158>. Acesso em: 04 de jul. 2020.

HILDEBRAND, NATÁLIA AMARAL et al. Resiliência e problemas de saúde mental em crianças e adolescentes vítimas de violência. Rev Saude Publica. 2019;53:17. Disponível em: $<\quad$ http://www.rsp.fsp.usp.br/wp-content/uploads/articles_xml/1518-8787-rsp-53-17/15188787-rsp-53-17-pt.x83745.pdf> Acesso em: 18 de mar. 2019.

THIOLLENT, Michel. Pesquisa-Ação nas organizações. São Paulo: Atlas, 1997.

TOLEDO, Luciano Medeiros de (Org.). Violência: orientações para profissionais da atenção básica de saúde. Rio de Janeiro, ENSP/FIOCRUZ, 2013. 36 p. 